\title{
Modelling of Aircraft Cabin Fires
}

\author{
E. R. GALEA and N. C. MARKATOS
}

Centre for Numerical Modelling and Process Analysis

Thames Polytechnic

Wellington Street

London SE18 6PF, UK

\section{ABSTRACT}

This paper presents a three-dimensional mathematical field model describing aircraft cabin fires. The computer code uses the body-fitted coordinate formulation which is used to model accurately the interior of the aircraft. The model is validated against experimental results obtained from a series of fire tests performed in a BOEING-737 fuselage (without fittings). Both steady-state and time-dependent results are presented. The effects of the aircraft's ventilation system on the temperature distribution within the fuselage is examined. Early results suggest that a reverse flow situation (i.e. cold air injected through floor vents and hot air sucked out at ceiling vents) greatly reduces the temperatures throughout the fuselage. Finally, there is an examination of the effectiveness of air curtains as a means of fire containment.

\section{Keywords}

Field model; Aircraft fire; PHOENICS; BFC.

\section{INTRODUCTION}

Aircraft accidents are often accompanied by fire. The large quantities of flammable fuel carried by modern aircraft $(214000$ and 105000 for the $B-747$ and $1-1011$, respectively) and the cabin design, which consists of a densely populated enclosure lined and furnished with organic (Jargely synthetic) materials $(4200 \mathrm{~kg}$ of such material is carried on a $B-747$ ) makes the possibility of fire a major concern.

Life threatening aircraft cabin fires belong to one of two groups, the so-called post-crash fire and the in-flight fire. In this paper we are primarily concerned with the in-flight fire scenario. In-flight fires mostly occur in accessible areas such as a galley or tollet. In the 20 years from 1964 to 1984 approximately 300 cases of in-flight fires have been reported, of these some 52 have proved fatal [1].

To uncover details concerning the fire-dynamics involved and the hazards responsible for preventing escape by passengers and ultimately their death, it is necessary to perform simulations of possible fire scenarios. The simulation may be either numerical, i.e. computer-based mathematical models or experimental fire tests. 
Mathematical modelling offers a cheaper and more general alternative to the experimental approach, provided that the models can be reliably validated. Both zone and field models have been implemented in describing aircraft cabin fires [1]. The zone modelling approach represents state-of-the-art technology currently in use; DACFIR [2], being the most sophisticated of the zone modelling packages available for aircraft fires. The field modelling formulation, while still in its infancy, is emerging as the 'new technology' for modelling of enclosure fires. It is already becoming a more widely accepted tool within the building fire community [3-5]. Previous attempts at modelling aircraft cabin fires using the field modelling approach have been confined to two-dimensional studies [6]. More recently satoh et al [7] have performed a three-dimensional simulation of an aircraft cabin fire; however, this study lacked an accurate description of the aircraft cabin geometry.

In the following sections a mathematical field model describing the in-flight fire scenario is presented and discussed. The model, still under development, attempts to simulate turbulent buoyant fluid flow and heat transfer within a realistically shaped aircraft cabin.

In an attempt to validate the numerical model, calculated results are compared with a set of experimental data from cabin fire tests conducted at the Johnson space centre [8]. These tests consisted of a series of 25 experiments conducted in a B-737 fuselage. Test 6 was chosen as the most appropriate for comparison purposes. In this test the cabin length was $17.1 \mathrm{~m}\left(104 \mathrm{~m}^{3}\right)$ with a cabin width at the floor of $3.3 \mathrm{~m}$ and a maximum cabin height of $2 \cdot 1 \mathrm{~m}$. The fire source was a fuel pan of dimensions $0.61 \mathrm{~m} \times 0.61 \mathrm{~m}$ centrally located on the floor. It contained $4.5 \mathrm{l}$ of Jet A-1 fuel, over the first 6 minutes of the burn this corresponded to a constant heat release rate of $239 \mathrm{kw}$. During the last 4 minutes the heat release rate had dropped to a constant $50 \cdot 7 \mathrm{kw}$. In test 6 , the fore and aft bulkhead doors (dimensions $1.5 \mathrm{~m} \times 0.9 \mathrm{~m}$ ) were left open allowing for natural ventilation. The ambient temperature was $29^{\circ} \mathrm{C}$. This cabin geometry was modelled accurately in three-dimensions using curvilinear BFC (Body Fitted Co-ordinate) grids.

Three sets of results are presented and discussed. The first group consists of a series of steady-state grid refinement/validation results simulating the near equilibrium conditions which develop after ten minutes of the burn. The fire is simulated by a volumetric heat source of $50.7 \mathrm{kw}$. The second group consists of a series of time-dependent simulations covering the first four minutes of the burn. The fire is sinulated by a $239 \mathrm{kw}$ volumetric heat source. The final group represents a fire situation similar to that in the first group with the additional feature of the cabjn environmental control system included. The environmental control system consists of uniform venting at the ceiling and floor. The cejling vents are situated at the top of the ceiling while the floor vents are located in the left and right corners where the side panels meet the floor. In addition to examining the case of uniform venting the effectiveness of an air curtain in containing the fire is examined.

\section{THE MATHEMATICAL PROBLEM}

The starting point of the analysis is the set of three-dimensional, partial differential equations that govern the phenomena of interest here. This set consists, in general, of the following equations: the continuity equation; the three momentum equations that govern the 
conservation of momentum per unit mass in each of the three space directions (the Navier-stokes equations); the equations for conservation of energy and species concentrations; and, the equations for a turbulence model (in this case the two-equation $\mathrm{k}-\epsilon$ model). The formulation of the differential equations describing the model will not be presented here as they may be found elsewhere [see $3,4,5,9]$.

The above-mentioned equations are transformed into general curvilinear coordinates, to allow for convenient and accurate treatment of irregularly shaped flow domains. The approach used here employs covariant physical velocity components in the form it appears in the general-purpose software package PHOENICS [10].

\section{The Grid and its Generation}

The BFC grid used can be considered as a distorted version of the usual orthogonal grid, in which grid lines and control cells are stretched, bent and twisted in an arbitrary manner, subject to the cells retaining their topologically cartesian character. This means that grid celis always have six sides and eight corners in the three-dimensional case.

The scalar variables solved by the BFC PHOENICS option are exactly the same as for the regular PHOENICS (see [9]). For details concerning grid generation and formulation of the conservation equations in $B F C$ mode see Hedberg et al [11].

\section{RESULTS AND DISCUSSION}

All numerical calculations were performed on the Thames Polytechnic NORSK 570 computers. Experience has shown that these calculations involve large quantities of computer tjme. A solution domain comprising of 4200 cells $(10 \times 10 \times 42)$ requires approximately 13 hours of cpu while a mesh of $20,328(22 \times 22 \times 42)$ cells requires in excess of 64 hours of cpu. The number of sweeps required to achieve convergence varies from 5500 to about 6500 .

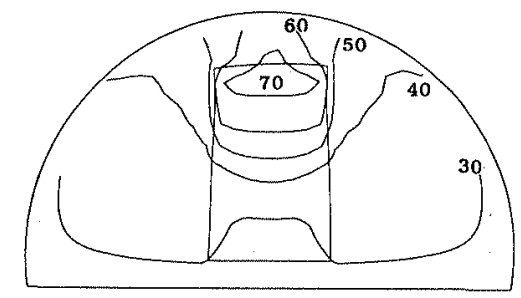

(a)

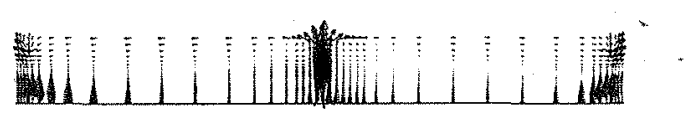

(b)

FIGURE 1. (a) Temperature contours $\left({ }^{\circ} \mathrm{C}\right)$ at aft doorway.

(b) Velocity field along the length of the fuselage passing through the heat source. $(50.7 \mathrm{~kW}, 22 \times 22 \times 42 \mathrm{grid})$. 
The first set of results relate to the grid refinement/validation series. The fire consisted of a $50.7 \mathrm{kw}$ heat source set in the centre of an empty $\mathrm{B}-737$ fuselage. The results were not found to be particularly sensitive to the number of cells in the $z$-direction (along the length of the cabin). It was found that 34 (interior) cells were adequate. The results were however strongly dependent on the mesh in the $x-y$ plane (i.e. the cylindrical cross sections). The meshes considered were $10 \times 10 \times 42 ; 16 \times 16 \times 42$ and $22 \times 22 \times 42$.

In order to find physically realistic results in the vicinity of the open doors it was necessary to extend the solution domain to regions outside the fire compartment. Four cells were used for this purpose at either end.

Figure 1(a) depicts temperature contours at the last exterior $z$ station near the aft door $(22 \times 22 \times 42)$. Figure $1(b)$ shows the velocity field along the length of the fuselage. The particular plane depicted passes through the open doors and the centre of the heat source. Note the relatively cool air (at higher than ambient temperatures) entering the cabin in the bottom portion of the open doorway and the tongue of hot air billowing out from the top section of the doorway. Figure 1(b) also shows the plume above the heat source and the ceiling jets away from the plume. In this plane a two-layered structure develops in the cabin atmosphere with small re-circulation regions near the floor sofits. The neutral plane is situated midway (51\%) in the open doorway.

The comparison between the numerical results and the experimental data is shown in figures $2(a)$ and 2(b). Figure 2(a) compares temperatures from the various grids with experimental data at a height of $0.5 \mathrm{~m}$ above the cabin floor, while figure $2(\mathrm{~b})$ is a comparison of the

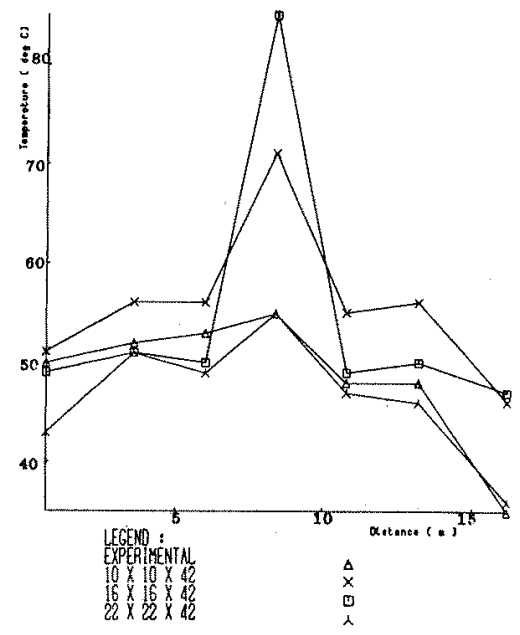

(a)

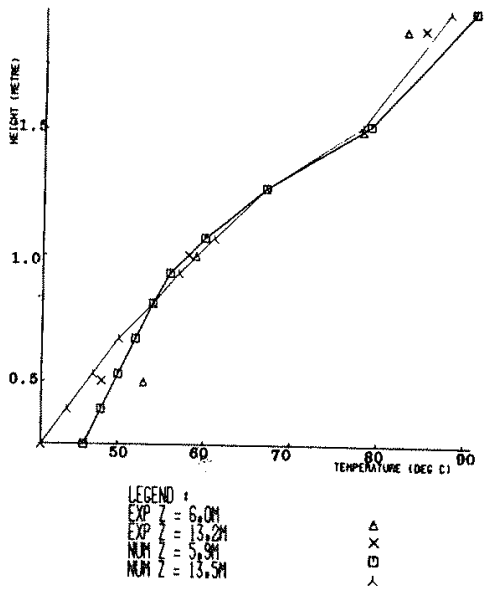

(b)

EIGURE 2. Numerical and experimental centreline temperatures $\left({ }^{\circ} \mathrm{C}\right)$ (a) Axial temperatures $0.5 \mathrm{~m}$ above the floor and (b) Vertical temperature stratification $(22 \times 22 \times 42 \mathrm{grid})$ at $6 \mathrm{~m}$ and $13.2 \mathrm{~m}$ from the aft doorway. 
experimental and predicted vertical heat stratification $6 \mathrm{~m}$ and $13 \mathrm{~m}$ from the open aft door at the centreline of the fuselage.

It should be noted that due to various uncertainties in the experimental measurements and also the lack of certain experimental detalls no effort was made to achieve perfect agreement between the experimental and numerical results.

It is clear from these results that there is good agreement between experimental data and numerical results $(22 \times 22 \times 42$ mesh $)$. The coarse grids (comprising of about 4200 cells), while not being able to predict accurately experimental temperatures, do follow the broad trends found in the experimental curves. These coarse grids are useful if qualitative rather than quantitative results are desired. With a solution domain comprising of $20,328(22 \times 22 \times 42)$ cells we are at the practical limit of the computer resources available at Thames polytechnic. clearly, in order to demonstrate grid independence solution domains in excess of $40,000 \quad(31 \times 31 \times 42)$ cells must be implemented. Considerably more effort must also be invested in the validation of the code.

Figure $3(\mathrm{a})$ shows temperature contours in a cylindrical section located approximately midway between the fire source and the open aft door. The atmosphere is clearly stratified into horizontal layers parallel to the floor. This is in agreement with experimental observations [12]. The air near the floor is heated to $42^{\circ} \mathrm{C}$ while air in the vicinity of the ceiling is heated to $88^{\circ} \mathrm{C}$. Figure $3(b)$ shows the velocity field in a cylindrical section through the fire plume. Entrainment of air into the plume and impingement of the plume at the celling and the resulting re-circulation region can be seen. Temper. atures within the plume are predicted to exceed $420^{\circ} \mathrm{C}$. A thermocouple station was located $0.3 \mathrm{~m}$ above the fuel pan. Temperatures of $300^{\circ} \mathrm{C}$ were recorded there. This compares with $319^{\circ} \mathrm{C}$ predicted by the model.

The next group of results concern the transient calculations. The calculations attempt to model the first four minutes of the burn. The fire consisted of a $239 \mathrm{kw}$ volumetric heat source. The grids used consisted of 4200 cells $(10 \times 10 \times 42)$ and 10,752 cells $(16 \times 16 \times 42)$. The preceding steady-state grid refinement series suggests that these meshes will not produce quantitatively correct results; however it does demonstrate the ability of the code to model the broad experimental trends.

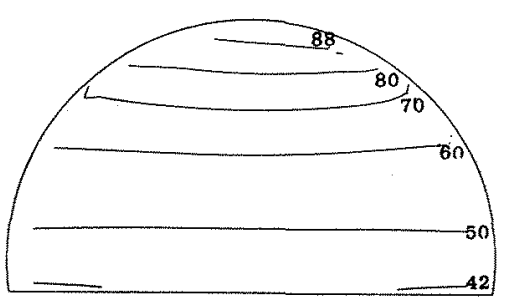

(a)

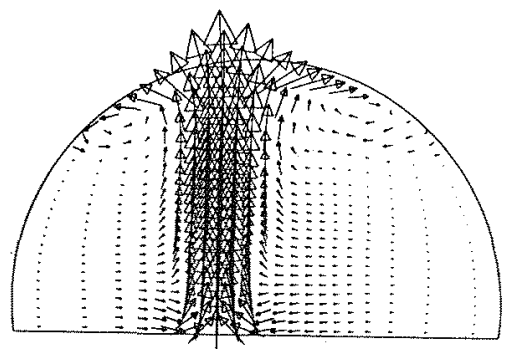

(b)

FIGURE 3 . (a) Temperature contours $\left({ }^{\circ} \mathrm{C}\right)$ through a cylindrical section located midway between the fire source and the open aft door. (b) Velocity field in a cylindrical section through the fire source. 

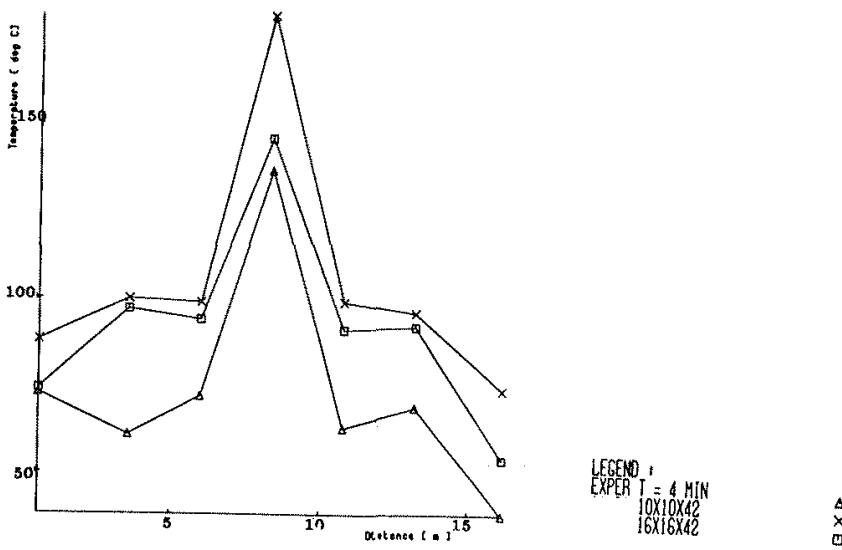

FIGURE 4. Numerical and experimental axial temperatures $\left({ }^{\circ} \mathrm{C}\right)$ for the $239 \mathrm{~kW}$ fire at $0.5 \mathrm{~m}$ above the floor after $4 \mathrm{minutes}$.

Figure 4 compares numerical and experimental temperature data at a height of $0.5 \mathrm{~m}$ above the floor. The figure depicts temperatures along the length of the B-737 fuselage 4 minutes after the fire was ignited. As was observed in the steady-state case, the broad trends found in the experimental curve are followed by the numerical curves. The finer mesh while still overestimating the experimental temperatures displays a marked improvement in predicting the maximum temperature at this height. It is expected that, as in the steady-stage case, the overall accuracy of the numerical results will increase as the grid is further refined.

The final group of results concerns steady-state numerical models which predict the effect of the cabin environmental control system on the heat flow in the B-737 fuselage. No experimental results are available for comparison. The solution grid used to produce these results consists of 4200 cells $(10 \times 10 \times 42)$ and the fire strength was $50.7 \mathrm{kw}$. As has been noted above, the mesh used here while not being able to produce quantitative results is expected to be qualitatively correct. The vents extend along the entire length of the cabin, the venting rate being $0.11 \mathrm{~m} / \mathrm{s}$. This rate corresponds to one complete air change every three minutes.

Three venting scenarios were investigated. In the first case, case $A$, fresh air is injected from the ceiling vents while hot air is sucked out from the floor vents. Case $A$ is intended to simulate the operation of the environmental control systems found in most commercial aircraft. In the second case, case $B$, this flow is reversed. The third case, case $C$, concerned the use of air curtains. Figures $5(\mathrm{a})$ and $5(\mathrm{~b})$ show temperatures along the length of the fuselage at $0.5 \mathrm{~m}$ (figure $5(\mathrm{a})$ ) and $1.5 \mathrm{~m}$ (figure $5(\mathrm{~b})$ ) above the floor for the three venting configurations and for the case with no venting. High up in the cabin all three venting configurations lead to a marked reduction in temperature along the entire length of the fuselage, venting case $B$ resulting in the largest reduction. At the $0.5 \mathrm{~m}$ height we find that venting case $B$ leads to the greatest reduction in temperatures while in venting case $A$ temperatures increase slightly. 


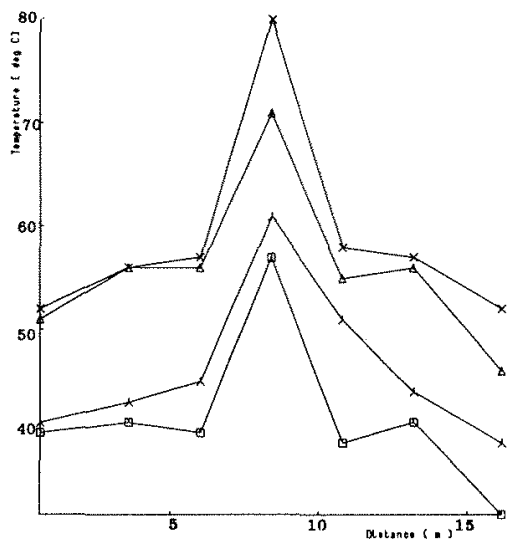

(a)

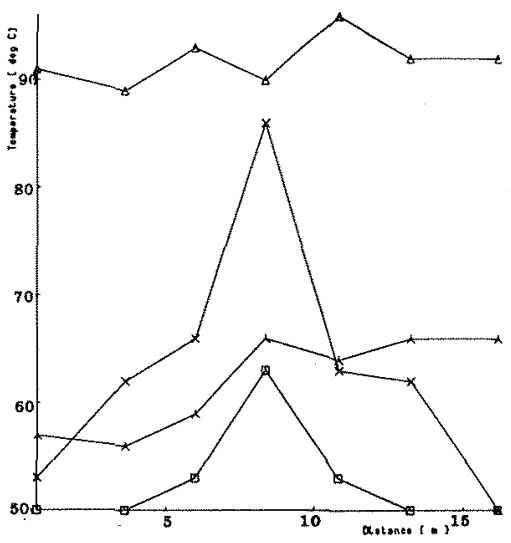

(b)

FIGURE 5. Numerical axial temperatures $\left({ }^{\circ} \mathrm{C}\right)$ for the various venting scenarios at (a) $0.5 \mathrm{~m}$ and (b) $1.5 \mathrm{~m}$ above the floor.

Figures 6(a), (b) and (c) show temperature contours in a cylindrical section located approximately midway between the fire source and the open aft door. Figure $6(\mathrm{a})$ is concerned with the case of no venting, while figure $6(\mathrm{~b})$ is concerned with venting case $A$ and figure $6(\mathrm{c})$ with venting case $B$. As can be seen venting at this rate does not greatly disturb the overall appearance of the cabin atmosphere. The atmosphere is still stratified into more or less horizontal layers in which the temperature increases from the floor to the ceiling. However, in venting case $A$ we find that the jet of cold air into the hot atmosphere does destroy the simple horizontal stratification near the ceiling (figure 6(b)). Two large cells of circulating air develop in the upper regions of the cabin extending along most of its length. These cells act to effectively mix the hot air and any fire products such as smoke and toxic gases. It is apparent from these results that floor suction (i.e. case A) tends to increase the temperature near the floor. The expulsion of gases from the floor vents attempts to reverse the natural tendency of hot air to rise.

It is recognised that in view of the fact that the model has not been completely validated by experiment, and due to the course nature of the grids used here, these results should be viewed with some degree of reservation. However, the usefulness of reverse venting in reducing temperatures and smoke concentrations near the floor in similar fire scenarios has been observed in full scale experimental room fires [13].

The final venting configuration investigated consisted of two air curtains placed either end of the heat source (case $C$ ). The air curtain was constructed by ceiling and floor vents as in case $A$ and $B$, however unlike the previous investigations the vents were placed in only two positions. The venting rate was $4 \mathrm{~m} / \mathrm{s}$ which results in one complete 


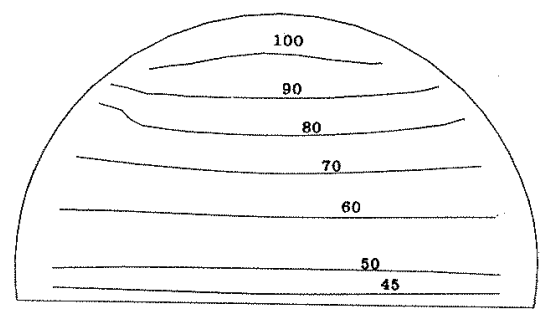

(a)

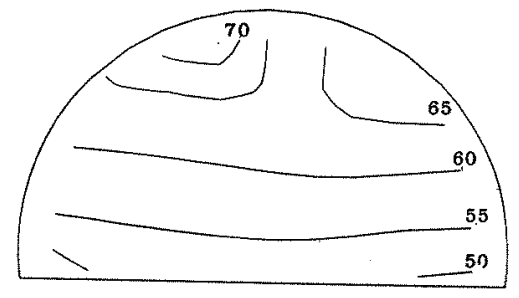

(b)

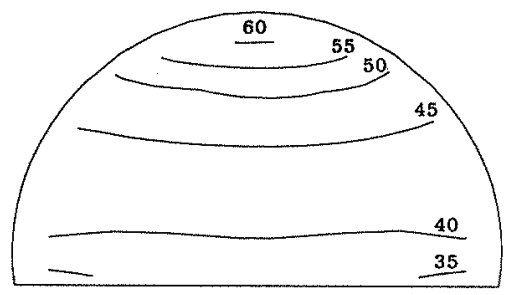

(c)

FIGURE 6. Temperature contours $\left({ }^{\circ} \mathrm{C}\right)$ in cylindrical sections located midway between the fire source $(50 \cdot 7 \mathrm{KW})$ and the open doorway $(10 \times 10 \times 42$ grid) for the cases (a) no venting, (b) venting case $A$ and (c) venting case $B$.

air change in 3 minutes. The airflow direction was as in case $A$.

Figures $5(a)$ and $5(b)$ show the effectiveness of using the air curtain to intercept the flow of hot air from the fire. Temperature along the entire length of the fuselage at both heights are reduced. At $0.5 \mathrm{~m}$ above the floor the temperatures fall between those found in cases $A$ and $B$. The temperatures are close to those found in the reverse flow configuration of case B. Higher up in the cabin at $1.5 \mathrm{~m}$ a similar situation occurs, however the temperatures near the ends of the cabin exceed those found in case $A$. As in the other cases the buoyant plume over the heat source is not washed out by the curtains.

\section{CONCLUSIONS}

The field modelling approach to predicting the behaviour of non-spreading fires in aircraft cabins has proved reasonably successful in simulating experimental fire tests. Meshes consisting of in excess of 20,000 cells are required if quantitative results are desired, however, as little as 4,200 cells will produce qualitative results. The use of BFCs have enabled realistically shaped aircraft fuselages to be modelled for the first time.

The action of the aircraft's ventilation system was observed to have a major effect on the temperature distribution within the burning fuselage. With the system blowing cold air from the ceiling vents and 
sucking hot air from the floor vents, as is found in most commercial passenger aircraft, temperatures near the floor are observed to increase. In the reverse flow situation temperatures decrease in the vicinity of the floor. Air curtains also prove successful in lowering the temperature near the floor. The use of these venting strategies could lead to control of the rate of spread of fire within the cabin. such control is particularly pertinent to the in-flight fire scenario.

Current research is directed towards extending the model to include: cabin fittings such as seats, overhead stowage bins, ceiling panels etc; a combustion model and a radiation model.

\section{ACKNOMLEDGEMENTS}

The authors would like to thank Mr Geoff Cox (Fire Research Station) and Mr Mike Shaw (Civil Aviation Authority) for many useful discussions. The authors are also indebted to the SERC for funding this research and to CHAM for allowing the use of PHOENICS.

\section{REFERENCES}

1. Galea E R and Markatos N C, App Math Mod 11, 162, 1987.

2. MacArthur C D, "Dayton Aircraft Cabin Fire Model, Version 3, Volume 1 , Physical Description", DOT/FAA/CT-81/69-T.

3. Kumar $S$ and Cox G, "Mathematical Modelling of Fires in Road Tunnels". 5th Int Conf on the Aerodynamics and Ventilation of Vech Tunnels, 1985, Lille, 61 .

4. Markatos $\mathrm{N} C$, Malin $M R$ and $\operatorname{Cox} G$, Int 3 Heat and Mass Transfer, $1982,25(1), 63,1982$.

5. $\operatorname{Cox} G$ and Kumar $S$, "The Mathematical Modelling of Fire in Forced Ventilated Enclosures", Proc $18 \mathrm{th}$ DOE Nuclear Airborne Waste Mange and Air Cleaning Conf, US Dept of Energy, Conf 840806, 1985, 629.

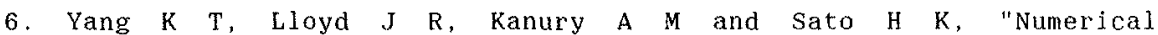
Calculations of Turbulent Buoyant Flow in Aircraft Cabins". DOT /FAA/CT-82/61.

7. Satoh $K$ and Kurvishi $T$, "Three-dimensional Numerical Simulations of Fires in Aircraft Passenger Compartments", 24th JAP Aviation Symp, $2 \mathrm{C}-8$, pp $1-4$.

8. Kuminecz $J F$ and Brickner $R$, "Full-Scale Flammability Data for Validation of Aircraft Fire Mathematical Models", NASA Tech Mem 58244,1982 .

9. Markatos N C and Cox G, Physico-Chem Hydrody, 5(1), 53, 1984.

10. Spalding D B, "A General-Purpose computer Program for Multi-dimensional One- and Two-Phase Flow", Prepr 81-6, Mathematics and Computers in Simulations, North Holland (IMACS), Vol XXIII, 1981, pp 267-276.

11. Hedberg P K, Rostin H I and Spalding D B, "The Phoenics Fquations", CHAM TR/99, october 1986. 
12. Sarkos C P, Hill R G and Howell W P, J Fire and Flammability, 13, 1982, 1972.

13. Meland 0 , "The influence of the ventilation system upon smoke-filled enclosures and the detection of smoke". "New Technology to reduce Fire losses and costs", Ed Grayson $S J$ and Smith D A, Proc Conf Lux 2-3 Oct 1986, p 316, Elsever App Sci 1986. 